\title{
Mecanismos de governação: 0 arbítrio e os costumes no processo de desenvolvimento da técnica legislativa portuguesa em relação às colônias brasileiras nos séculos XVI e XVII. ${ }^{1}$
}

Elaine Godoy Proatti ${ }^{2}$

\section{Resumo}

Apresentarei as tensões e acomodações entre as leis régias e os costumes presentes na América portuguesa no século XVI e metade do XVII, identificados na análise dos "Regimentos e Instruções para o Brasil" e nos primeiros Autos de Correições de Ouvidores Gerais do Rio de Janeiro.

Procurarei mostrar como os costumes e o arbítrio dos juízes, na interpretação das leis régias, constituíram-se em mecanismos de governação que tornaram possíveis a construção e o funcionamento da sociedade na América portuguesa.

\footnotetext{
${ }^{1}$ Esta pesquisa faz parte do projeto "Direito e Justiça nas Américas" do Professor Doutor Rafael Ruiz, aprovado com o auxílio da FAPESP e do grupo de pesquisa "Núcleo de Estudos Ibéricos" da Universidade Federal de São Paulo envolvendo outros alunos. Agradeço à FAPESP pelo apoio aos dois projetos de Iniciação Científica: "Regimentos e Instruções para o Brasil (séc. XVI-XVII) aprovado dentro do período de 01/04/2010 a 31/03/2011, e: "Autos de Correições de Ouvidores do Rio de Janeiro (1624-1699) aprovado dentro do período de 01/02/2012 a 30/11/2012. Agradeço também ao Arquivo Geral da Cidade do Rio de Janeiro pela concessão dos documentos aqui utilizados.

2 Aluna de Graduação na Universidade Federal de São Paulo - Campus Guarulhos/ SP, $5^{\circ}$ Ano, ( $9^{\circ}$ termo).
} 


\section{Cadernos de Clio, Curitiba, n. ${ }^{\circ}$ 3, 2012}

Palavras-chaves: Arbítrio - Costumes - Legislação - Justiça América portuguesa.

\section{Introdução}

Esta pesquisa compartilha das hipóteses do projeto "Direito e Justiças nas Américas" que pretendem mostrar as ambigüidades e flexibilidades ocorridas entre a legislação régia e as diferentes realidades locais na América colonial, especificamente por meio das sentenças e decisões finais dos juízes e ouvidores. Procurará mostrar as tensões, conflitos, negociações e acomodações entre as leis, as determinações régias e os usos e costumes introduzidos na América portuguesa no século XVI e na primeira metade do XVII, identificados na análise dos "Regimentos e Instruções para o Brasil" e nos primeiros anos dos Autos de Correições de Ouvidores Gerais do Rio de Janeiro.

Reunidos por Marcos Carneiro de Mendonça, os "Regimentos e instruções para o Brasil" presentes no primeiro volume de Raízes da Formação Administrativa do Brasil compreendem os anos de 1548 a 1612 e nos mostram que a aplicação da justiça era uma das principais preocupações da monarquia desde os primórdios da colonização portuguesa. O oficial, ao assumir um cargo, recebia um regimento feito com base na legislação vigente que orientava a atuação e as atividades desse oficial, estabelecendo a sua jurisdição e os limites da sua alçada. 
Já a análise dos Autos de Correições de Ouvidores Gerais do Rio de Janeiro de 1624 a 1661, compreendidos no primeiro volume que se estende até o ano de 1699, e coletados por Eduardo Tourinho, nos apresenta a vida administrativa judiciária da cidade de São Sebastião do Rio de Janeiro e nos indica como os juízes regionais e de segunda instância realizavam o exercício das suas funções, fiscalizando, tomando residência e corrigindo as decisões e sentenças dos juízes locais.

A partir da leitura dos regimentos, que norteavam as ações dos oficiais e dos Ouvidores Gerais, e das correições anuais que estes oficiais faziam, podemos levantar e compreender algumas atividades, conflitos, autonomias e limites que estariam na incumbência desses oficiais nos exercícios de suas práticas efetivas.

Para visualizar a lei nos domínios portugueses, através dessa pesquisa documental, faz-se necessário lidar com questões como o espaço para o arbítrio do funcionário real, a divisão e distribuição de poderes entre as autoridades, o conflito de jurisdições, a persistência do rei em querer ser informado sobre tudo o que ocorre nessas terras coloniais, os processos de decisão, a aplicabilidade e vigência da lei, a conseqüente ambigüidade, negociação e adaptação realizadas para relacionar a norma régia e as práxis administrativas. 


\section{Debate historiográfico}

O debate ocorrido nos anos 70, com os estudos de Stuart Schwartz ${ }^{3}$, contribui para uma melhor compreensão da estrutura judicial portuguesa na colônia. Iniciada em 1580, essa estrutura criada no Brasil seguia os padrões do governo e das instituições oficiais de Portugal e acompanhava os seus desfechos e desenvolvimentos (SCHWARTZ, 1979: 04).

O sistema judiciário funcionava para a coroa portuguesa como um instrumento de extensão do seu poder real. Administrar tal sistema significava manter e reforçar a presença desse poder real e controlar seus domínios. E, para isso, a metrópole contava com os magistrados reais e demais oficiais régios enviados às colônias com funções administrativas e judiciárias para garantirem a vontade do rei e protegerem seus interesses expansionistas. A lei portuguesa tornava-se a lei dos territórios conquistados e ministros da justiça, a exemplos dos de Portugal, assumiam cargos coloniais a fim de fazer cumprir a lei (SCHWARTZ, 1979: 15).

\footnotetext{
${ }^{3}$ Para este autor, o estudo sobre a administração da justiça na colônia se faz muito pertinente nas pesquisas sobre a administração colonial, a sociedade e suas burocracias por enxergar no sistema judiciário um esquema estrutural do império. Ou seja, a organização judicial é para ele uma chave, um ponto que sustenta toda uma malha imperial. Ela era organizada, racionalizada e sistematizada desde o século XIV para oferecer à coroa os meios burocráticos de controle colonial por meio de seus magistrados reais enviados aos seus domínios. (SCHWARTZ, 1979: 17).
} 
António Manuel Hespanha entra nesse debate por volta dos anos 80/90, questionando uma série de idéias estabelecidas sobre a constituição moderna portuguesa. Ele suspeita de uma forte presença de poderes, especificamente, das câmaras e das instituições eclesiásticas ou senhoriais, que tiravam proveito da fragilidade do poder régio, no que diz respeito aos seus aspectos doutrinais e institucionais, para ganhar um espaço de efetiva, ainda que discreta autonomia. Para ele, todas as normas devem valer integralmente, uma nuns casos, outras nos outros. Desta forma, cada norma funciona como uma perspectiva de solução do caso, mais eficaz ou não, de acordo com a hierarquia dessa norma, e, sobretudo, conforme a sua adaptação à situação.

Dentro desse debate, a partir de 2000, Laura de Mello e Souza apresenta as duas principais interpretações historiográficas sobre a administração colonial apontando a ambigüidade e as contradições que nelas existem. Tem como idéia que a administração colonial só podia ser entendida à luz da política, e que separá-las significava ter uma apreensão "mecânica e funcionalista do fenômeno, impondo a perda do seu sentido dialético" (SOUZA, 2009: 66). Este sentido dialético apontado pela autora se faz interessante por permitir a visualização das ambigüidades existentes nas práticas políticas e administrativas, e tais espaços aberto podem ser encontrados no exercício da justiça e do direito. 
Neste mesmo período, Sílvia Hunold Lara analisa os direitos e justiças no Brasil demonstrando que a justiça operava reforçando a imagem do rei reativando sua soberania e reiterando a obediência de seus súditos. Ela era evocada sempre para consolidar a legitimidade do poder régio, reforçar os laços hierárquicos e marcar o domínio do monarca sobre todos os territórios conquistados (LARA, 2006: 86).

Recentemente, outros historiadores continuam a estudar a administração da justiça no Brasil e oferecem novos pontos de vista acerca de sua estrutura e desenvolvimento ${ }^{4}$.

\section{Administração no ultramar: espaço específico e circunstanciado}

Considerando a época e o lugar específicos dos domínios portugueses, o campo de possibilidades da aplicação efetiva da lei régia era diverso e dependia das necessidades do momento. A vigência da legislação básica portuguesa na colônia, no exercício das Ordenações, dava-se na adaptação às condições do meio, já que haviam sido feitas "não havendo respeito aos moradores do Brasil" (MENDONÇA, 1972: 57) e segundo o primeiro ouvidor-geral do

\footnotetext{
${ }^{4}$ Para uma leitura mais aprofundada sobre esse debate ler Maria de Fátima Gouvêa, Maria Fernanda Bicalho, Rodrigo Bentes Monteiro.
} 
Brasil Pedro Borges ${ }^{5}$, sem nenhum regimento, "alguns serviram sem juramento (...) viviam sem lei, nem conheciam superior" (MENDONÇA, 1972: 55).

As leis, até alguns anos do século XVIII, podiam ser desobedecidas e ainda impugnadas na sua validade, e os motivos eram variados. Os obstáculos da distância, da informação distorcida, do caráter exótico e diferente da colônia, bem que poderiam explicar a falta de informação e a possibilidade de contestação jurídica das leis régias (HESPANHA, 2006: 100).

Em virtude destes obstáculos verifica-se que muitas vezes a legislação régia enviada para a colônia portuguesa não era aplicada efetivamente. As condições diversas e variantes da realidade americana mostram que a aplicação das leis gerais não se dava facilmente, e que se fazia necessária outra maneira para tal exercício.

Essa outra maneira era a interpretação da lei baseada na própria consciência dos juízes locais. Os juízes precisavam considerar, nas suas sentenças, as circunstâncias e as especificidades locais. Eles poderiam julgar cada caso conforme as suas consciências e optar não pela lei régia propriamente dita, tendo em vista que esta muitas vezes não concordava com as realidades da

\footnotetext{
${ }^{5}$ Carta do ouvidor-geral Pedro Borges ao rei D. João III em 07 de fevereiro de 1550. Nesta carta o ouvidor reclama a falta de Justiça, de ordem e de oficiais mais capacitados para os cargos administrativos e judiciais.
} 
colônia, mas sim, pela opinião que lhes parecesse mais provável. Tal maneira de aplicação da lei na América facilitou para que os poderes locais tivessem um amplo e ambíguo espaço de atuação jurídica, podendo considerar os costumes como formadores do direito ao invés da lei (RUIZ, 2010:93). Com esta possibilidade posta, criava-se no campo jurídico uma distância entre a norma régia e a prática legal.

E é nesta distância entre a norma régia e a prática legal que podemos encontrar espaços de ambigüidade, de conflito, negociações e de autonomia das autoridades local, entendendo o costume como um criador do direito, e não apenas a lei régia. Isto permite pensar em variadas maneiras de se exercer o poder judiciário, em lugar de uma única maneira.

Com esta possibilidade aberta, coloca-se a questão da finalidade das instituições governamentais e as condições especificas da sociedade, entendida como ordem pública, baseada em seus costumes, confrontada com a norma geral, que se pretende universal, mas que não é compatível com a realidade na América. A organização política e social na América portuguesa não se baseava nos costumes locais e nas especificidades do espaço colonial regidas por uma ordem pública. $\mathrm{O}$ aparelho governamental régio, orientado pela norma geral, que se pretendia universal, vinda da Coroa por meio de Regimentos, Instruções e Ordenações aplicado na colônia não condizia com as realidades práticas e concretas desta 
(MENDONÇA, 1972:06). Portanto, na prática, tais normas gerais eram desconexas e imperfeitas para serem efetivamente aplicadas com fim ao bem comum a um espaço específico e circunstanciado. Necessitava-se de um direito que se adaptasse e se flexibilizasse às particularidades do lugar para que se aplicasse a justiça de forma prudente.

Deste modo, no campo das circunstâncias, um fator que fornece autonomia ao direito da colônia encontra-se nas relações entre Direito Geral e Direito particular, presente na ordem jurídica do século XVI e XVII (HESPANHA, 2006:103). De forma geral, mesmo que as normas particulares não tivessem validade contra o direito comum do reino enquanto manifestação de um poder político, estas normas conseguiam derrogá-lo enquanto manifestação de um "Direito Especial", válido dentro da jurisdição régia sem desobedecer à lei. Ou seja, os juízes, seguindo as especificidades do espaço colonial, rejeitavam o direito comum vindo do rei para produzirem um direito particular proveniente das normas particulares, dos costumes locais e do arbítrio, e isto, sem desobedecerem ao rei.

Desta forma, percebe-se o quão restrito era o poder do rei, fazendo prevalecer, numa sociedade corporativista típica de Antigo Regime não apenas a lei, como única forma legal de se estabelecer Justiça, mas outros princípios éticos e morais que também levassem ao bem comum. Se o rei tinha o seu poder restrito, os juízes, pelo 
contrário, seguindo a doutrina de Teologia Moral Probabilista ${ }^{6}$, detinham um amplo e ambíguo espaço jurídico para exercerem sua função de decidir justamente sobre as circunstâncias concretas de cada caso.

Seguir a própria consciência era, para os juízes, elaborar um juízo decisório sobre um caso concreto, a partir do seu entendimento, tendo em conta não apenas a lei, mas principalmente as circunstâncias concretas que especificavam o caso (RUIZ, 2009:74)

Deste modo, podemos apontar o arbítrio e os costumes como mecanismos de governação administrativo e legislativo, na criação do Direito e da Justiça na América portuguesa.

\section{Usos dos "usos e costumes"}

A noção de "usos e costumes" aparece nos documentos sempre como um endosso argumentativo que reforça a aplicabilidade da lei ou a sua proibição. A diferença entre os dois casos está na interpretação que os oficiais régios e as autoridades locais fazem dessa práxis, considerando-a legítima ou não para a legislação colonial. Ou seja, não há um único costume referenciado nos regimentos e ordenações com validade legal ou não, há o

\footnotetext{
${ }^{6}$ Com relação a este tema, especificamente, pode-se ler RUIZ, (2010).
} 
costume vindo do reino e os costumes locais. Mostraremos alguns exemplos retirados dos "Regimentos" e dos Autos de Correições que explicitam os costumes como mecanismos de governação no desenvolvimento da técnica legislativa portuguesa.

Um ponto importante a ser ressaltado no Regimento XII sobre o novo tribunal da Índia e mais Estados Ultramarinos são as orientações iniciais dadas pelo rei:

Eu El Rei, faço saber aos que este meu Regimento virem, (...) ficando reservado a mim tirar, mudar e acrescentar nele o que houver por mais meu serviço, conforme ao que a experiência for mostrando que mais convém (MENDONÇA, 1972: 349).

Ele deixa claro que a lei somente poderá sofrer adaptações, mudanças ou derrogações sob o seu poder régio, e isto conforme a sua experiência lhe mostrar que melhor convém.

No capítulo 79 do "Regimento XV do Tribunal da Relação da Bahia" fica claro que o provedor não pode agir de outra maneira que não seja a de costume real e não lhe é negociada outra forma de aplicabilidade dessa norma. É ordenado que se cumpra, guarde e use o "Regimento":

(...) sem embargo de quaisquer outros Regimentos, Leis, provisões e Costumes que, em contrário, sejam 
Cadernos de Clio, Curitiba, n. ${ }^{\circ}$ 3, 2012

passados, os quais Hei por derrogados, e quero que se não cumpram, nem tenham força, nem vigor algum, nem se guardem no que a este encontrarem (MENDONÇA, 1972: 398).

Tal "Regimento" reforça a idéia anterior de que apenas o rei pode alterar a lei e que outras formas, como leis, provisões e costumes não terão validade legal e não serão aceitos.

No "Regimento XIII da Casa de Suplicação" aparece no capítulo primeiro e sexto a distinção feita entre os costumes régios e os coloniais, mostrando o quanto pode ser ambígua a decisão do rei para com esse mecanismo. No primeiro capitulo é ordenado que em todo o tempo que durar o despacho, a porta da Relação da Casa da Suplicação esteja fechada como costuma estar em todos os mais tribunais (MENDONÇA, 1972: 355). O que cabe perceber aqui é quais são os usos e costumes que interessam ao rei e quando eles são invocados como forma de reforçar e legitimar a autoridade real e rejeitados quando interferem nos assuntos reais.

No capitulo sexto deste mesmo "Regimento", o termo "costume" é empregado com a seguinte intenção: neste item, em que todos os escrivães devem levar os feitos à casa dos desembargadores:

(...) e que nenhum Escrivão do Crime possa trasladar as devassas, senão por sua própria mão, sem embargo 
Cadernos de Clio, Curitiba, n. ${ }^{\circ}$ 3, 2012

de qualquer uso, costume, ou sentenças que houver em contrário, porque tudo Hei por derrogado, (...) e que hajam por isso as penas que bem parecer ao Regedor (MENDONÇA, 1972: 357).

Este trecho evidencia que quando o assunto interessa ao rei, como as informações e devassas da Casa de Suplicação, a lei deve ser cumprida e os "usos e costumes" contrários a ela, sendo régios ou locais, não podem desviá-la. Mas, que quando a situação couber para os assuntos prementes na colônia, como as penas aos que não cumprirem a norma, estes sim ficam ao parecer do Regedor. E dentro do parecer do Regedor há a possibilidade de se fazer uso dos "usos e costumes" conforme a sua prudência lhe mostrar necessário. Ou seja, para garantir o cumprimento da norma régia, o regedor tinha autonomia para sentenciar conforme melhor lhe parecer, nem que para isso se utilizasse do costume local.

O rei, no "Regimento da Relação da Casa do Brasil" para o ano de 1609, não abre espaço para negociação e adaptação quando isto vem a ameaçar o cumprimento da lei e a conservação e preservação da imagem do poder real. Esta não abertura, por outro lado, evidencia que há um conflito e uma tensão ocasionados pela possibilidade de revogar a lei e adaptá-la com os "usos, costumes," leis e provisões anteriores. Visto que uma lei pode alterar-se uma vez que a anterior não estiver em consonância com as necessidades 
locais. Ou seja, o monarca, não aceitando a interferência dos costumes locais na aplicação da norma e no processo legislativo, de forma a adaptá-la para melhor caber e corresponder às circunstancias do espaço colonial, abre possibilidades para as autoridades locais agirem conforme melhor lhe parecerem.

Este "Regimento" mostra também uma preocupação para com a autonomia dos poderes locais, que freqüentemente está sendo limitada. A autonomia, parece, é concedida nos casos particulares da colônia em que não cabe ao rei a atenção e garantia de cumprimento da norma régia. Nessas situações é que os poderes locais têm arbítrio para aplicarem a lei como lhe bem parecer ao bom exercício da Justiça.

O rei, ao usar o costume régio de maneira a reforçar e legitimar sua autoridade para garantir a aplicabilidade e a vigência da lei, confere a esse costume um grau de normatividade.

No Auto de Correição de 1630, o Ouvidor Geral Luiz Nogueira de Britto perguntou aos oficiais da Câmara se haviam algumas posturas que desencontrasse ao bem comum, foros e costumes. Estes responderam que não, salvo o foral sobre 0 Alcaide- Mor. O ouvidor tornou a perguntar para os oficiais se estava em costume essa atitude a respeito do foral e eles lhe responderam que não. Assim sendo, o Ouvidor Real mandou que lhes acudissem a sua obrigação e a sustentar os foros e costumes antigos dando-lhes em culpa se não os fizer (TOURINHO, 
1929:19). Este exemplo mostra a preocupação do oficial da Coroa em manter e fazer cumprir o costume régio antigo, tradicional, proibindo, assim, a ação de qualquer outro costume local que impedisse o primeiro.

Outro exemplo da preocupação na preservação do costume régio encontra-se no Auto de Correição de 1655 quando o Ouvidor Geral João Velho de Azevedo aponta que o costume, "tão antigo e santo", das procissões e ladainhas estava sendo perdido. Proveu o Ouvidor que se fizessem as ditas procissões:

\begin{abstract}
(...) como era uso e costume e sendo necessário para isso dar-se parte ao Prellado, para que obrigue aos Clérigos hirem nellas, os officiaes da Camara lhe faram saber. (TOURINHO, 1929: 43).
\end{abstract}

Esta provisão nos mostra que, para além da preocupação régia em manter o costume santo vindo de Portugal, os clérigos que não o cumprissem eram acusados e obrigados a responder no Conselho da Câmara.

Tanto nos "Regimentos" quanto nas Correições está indicado que os costumes régios eram mantidos e preservados e que quaisquer outras formas como leis, usos e costumes locais contrários ao ordenado não teria validade, força nem aplicabilidade legal. Se as determinações régias conservavam o seu costume, o 


\section{Cadernos de Clio, Curitiba, n. ${ }^{\circ}$ 3, 2012}

oficial real, no exercício de sua função, também prezava para o cumprimento deste, sem deixar de apontar que existiam outros costumes e que estes preocupavam ao rei.

Ao comparar nos documentos analisados os usos que se faz dos costumes reais com os usos dos costumes locais percebe-se que não há interesse, por parte da metrópole, em considerar o local como um princípio de interpretação e de aplicação da lei. Tal posição nos permite apontar que, para o costume régio servir como um mecanismo de governação da Coroa na colônia, ele adquire uma função normativa e para isso desconsidera o costume local. Dentro das normas régias, o costume régio é a lei e o costume local não. Mas o juiz, dentro do seu espaço de autonomia conferido pelas circunstâncias e especificidades coloniais, pode usar o costume local como um princípio interpretativo, dentre outros, pelo qual poderia valer-se para deliberar sua sentença e transformar esse costume em um mecanismo legal com função normativa, para o caso em particular.

\section{O arbítrio como mecanismo de "governação"}

O livre arbítrio é entendido neste trabalho como a liberdade de decisão que os juízes dispunham para sentenciar conforme a sua consciência. A questão que se coloca é a seguinte: poderiam os juízes ter liberdade para flexibilizar as leis ou estavam obrigados a segui-las literalmente? 
A questão que permeia este item é a de qual autonomia os poderes locais detinham. Se esta era precisada em virtude das circunstâncias e das especificidades do espaço colonial, encontradas na distância entre a colônia e a metrópole; ou se era cedida às autoridades locais a fim de reforçar o poder real através das ações desses agentes. Assim como perceber quão autônomos e livres eram esses juízes e até que ponto, efetivamente, a autonomia deles tinha vigor e legitimidade. $\mathrm{O}$ que os regimentos e a análise dos "usos e costumes" nos mostram é que a autonomia dada para as autoridades locais diz respeito aos assuntos que não interferem diretamente na lei, mas no seu cumprimento e, portanto, na sua interpretação. Para os assuntos específicos, de ordem prática, como a aplicação de um castigo ou o valor do tributo, cabe ao juiz escolher "como lhe bem parecer" (MENDONÇA, 1972: 270), “conforme lhe parecer Justiça" (MENDONÇA, 1972: 306), agir para o "bem comum" (TOURINHO, 1929:19), para o “bem da República” (TOURINHO, 1929: 10). Estes termos presentes nos regimentos parecem-me que demonstram o espaço que o rei confere ao julgador colonial para este atuar de acordo com o seu arbítrio. Tal espaço, em alguns casos é cedido para o juiz local e em outros, segundo as especificidades e particularidades locais, é negociado e acomodado pela própria autoridade na colônia.

Desta forma, pode-se deduzir que o arbítrio não está dissociado dos costumes. Assim como a experiência é um 
argumento forte que representa um fator a mais a ser levado em conta na decisão do juiz. A experiência, de modo prático, mostra o que vai ou não ser alterado, dependendo do sucesso e interesse no assunto. Quando esta é utilizada como referencial de bom governo, ela pode ser orientada pela consciência e prudência do juiz, cabendo a ele escolher, segundo o que lhe parecer mais provável, como proceder. Neste caso, o costume, orientado pela experiência do juiz, tende a ser uma ferramenta de interpretação da lei.

Parece-me, portanto, que o juiz pode escolher agir conforme os costumes locais ao invés das leis régias, se assim lhe parecer bem ao bom governo e cumprimento da Justiça e corresponder à melhor maneira de aplicá-la. Ele não estará, deste modo, deixando de obedecer ao rei quando lhe é pedido para que faça de acordo com o que julgar pertinente; estará exercendo, pelo contrário, o seu arbítrio da maneira que a sua consciência lhe mostrar mais provável interpretar o caso. A exemplo, temos o capítulo 12 da carta de Pero Borges a D. João III, em 07 de fevereiro de 1550, referente à como se proceder em um Julgamento:

(...) e acontecem mil casos que não estão determinados pelas Ordenações, e ficam ao alvedrio do julgador, e se nestas se houver de apelar, não se pode fazer justiça, e são às vezes casos tão leves que é cruza apelar neles, e estarem os homens em terra tão pobre, esperando por suas apelações, mande V. 
Cadernos de Clio, Curitiba, n. ${ }^{\circ}$ 3, 2012
A. ver isto e mande prover, se for seu serviço (MENDONÇA, 1972: 56).

O "Regimento dos Ouvidores Gerais" mostra que há uma confusão da jurisdição administrativa e tenta controlar o poder para evitar os espaços de ambigüidade. Exige-se, neste regimento, para as penas graves a concordância do parecer dos juízes, instituindo o recurso de agravo ou apelação para outra autoridade em caso de divergência de opinião entre os julgadores. Ou seja, questões ambíguas permitem tensões e flexibilidades entre as instâncias locais dependendo da consciência de cada um. Há também o recurso para o Tribunal de Relação da Bahia, que de modo mais claro consolida a divisão de poderes.

O conflito de jurisdição, ocasionado pelos espaços de autonomia e as ambigüidades provenientes dessas, é resolvido pedindo que se haja de acordo com o prudencialismo de cada autoridade; prudencialismo este pedido pelo rei como uma forma de conduta do julgador presente no capítulo 21 do "Regimento VIII de Francisco Giraldes":

(...) e em caso, que o Bispo não proceda bem, e se queira intrometer, o que não creio dele, acudireis a isso com vossa prudência, não lho consentindo, e me avisareis logo de tudo; e intentando sobre esta matéria alguma excomunhão, conhecerá do agravo 
Cadernos de Clio, Curitiba, n. ${ }^{\circ}$ 3, 2012

dela como costuma fazer o Juiz dos Feitos da Coroa e da Fazenda da dita Relação; assim como, em tais casos, conhece neste Reino o Juiz de meus Feitos(MENDONÇA, 1972: 265).

Neste outro exemplo percebe-se a relação entre a norma e a práxis colonial porque aparece pela primeira vez a possibilidade de suspensão de um capítulo da lei régia executada por uma autoridade que não é a real. E esta possibilidade está normatizada, o que pode significar um espaço de negociação e de adaptação da lei, no qual se desenvolve a técnica legislativa portuguesa relacionada com as práticas administrativas coloniais, como se verifica neste "Regimento das Minas de Ouro de São Paulo":

(...) O Superintendente terá jurisdição ordinária, cível e criminal, idênticas aos juízes de fora e ouvidoresgerais das Comarcas do Brasil; o Superintendente, não concordando ou entendendo dever alterar alguns capítulos, informará e suspenderá a sua execução (MENDONÇA, 1972: 346).

Há um espaço de negociação e adaptação da norma régia de acordo com o arbítrio do juiz e com as circunstâncias que para ele se mostrarem mais pertinentes para a aplicabilidade da lei. Juntamente com essa identificação do espaço de negociação e 
adaptação da lei, há a preocupação real com o quão autônomos podem ser essas autoridades locais, a ponto de agirem sem ordenação. O rei está interessado em controlar esse espaço de negociação e adaptação quando percebe que os poderes locais podem escapar à sua regência.

Tal situação ocorre porque normalmente cabe ao rei revogar, adaptar e alterar a lei, mas, como observado nos documentos, o juiz local, em seu espaço de autonomia, fazendo o exercício de seu arbítrio, seguindo sua experiência e sua consciência, pode optar, de acordo com a sua interpretação, pela opinião que lhe parecer mais provável, seja esta dada pelo costume local, pela opinião dos doutores, pelo bem e necessidade da res publica e pela não recepção da lei.

\section{O Justo segundo a interpretação do juiz}

O juiz no século XVII tinha a função de dizer o justo e de ditar um conjunto de direitos e deveres. Essa função the era atribuída pela organização social (HESPANHA, 2001:118) e demonstrava que a definição de justo ou injusto não era algo da vontade do homem, do indivíduo, mas algo da função de ser juiz. E além de dizer o justo, também é da função do juiz realizar o bem 
comum, porque o fim próprio de cada lei é o bem comum de todos ${ }^{7}$. Então, no exercício de sua função, para o juiz dizer o justo, que comportava o bem comum, o que lhe parecesse conveniente à República e ao bom governo da Justiça, este interpretava os fatos e arbitrava as sentenças ${ }^{8}$. Ficavam ao arbítrio do juiz os casos que não estavam definidos pelo direito, e as sentenças desses casos dependiam da interpretação que o juiz fazia sobre eles.

Para que o juiz pudesse sentenciar era preciso que deliberasse em consciência sobre qual seria a solução mais justa e, para tanto, precisava, de forma geral, interpretar a lei. De acordo com a sua interpretação, o juiz podia se utilizar do costume local, da opinião mais provável, das leis reais, dos foros, do que considerava justo seguindo a sua consciência:

Esse 'deliberar em consciência' significava que a sua decisão formava-se no seu foro interno e, portanto, estava delimitada dentro do âmbito da Teologia moral. (RUIZ, 2011:06)

\footnotetext{
${ }^{7}$ Tomás de Aquino nos esclarece melhor sobre a finalidade e a essência da lei nessa passagem de sua obra: "A lei não é outra coisa que uma ordenação de razão para o bem comum, promulgada por aquele que tem o cuidado da comunidade". (AQUINO, 2005:527).

${ }^{8}$ Antonio Manuel Hespanha coloca que mesmo as normas de direito comum procederem da razão, isto não sustentava a elas uma vigência superior, ao passo que da mesma razão provia a capacidade de cada cidade de corrigir ou adaptar-se em meio às situações concretas (HESPANHA, 2006:116).
} 
Dentro da interpretação do juiz, a sua consciência era muito importante para se compreender a sentença dada por ele. $\mathrm{O}$ sistema jurídico, baseado na tradição prudencialista, era amparado na ação do juiz que poderia julgar seguindo a sua própria consciência (PRODI, 2005: 211).

A interpretação da lei feita pelos juízes e ouvidores gerais demonstra e auxilia na criação do Direito na América portuguesa e na aplicação e entendimento da lei no caso concreto que, independente dos meios e argumentos tais como os costumes, a prudência e consciência do julgador, o bem comum da res publica, a ação conforme a experiência, configura um caráter político e moral. Ou seja, é através da interpretação do juiz que podemos observar como se dá a relação entre a norma escrita, determinada nas leis régias, e a práxis colonial apoiada nos usos e costumes. Desta forma, é na relação entre o Direito e a Teologia Moral Probabilista (que norteia a ação do juiz em sua função) que entendemos melhor o processo da administração judicial na colônia portuguesa e conseguimos apontar o arbítrio, os costumes e a consciência do julgador como alguns mecanismos de governação para esse lugar circunstanciado no período do Antigo Regime.

A interpretação, nesse caso, assume um papel essencial na descoberta da vontade do legislador, criticando assim, as interpretações artificiais e o abuso de artifícios retóricos. Ou seja, a conclusão mais relevante é a de que a disciplina da interpretação e 
aplicação da lei tem inegável caráter político (HOMEM, 2003: 177).

\section{Conclusão}

No desenvolvimento da técnica legislativa portuguesa em relação às colônias brasileiras, as implicações entre as normas régias e as práxis coloniais abrem espaço para a negociação, adaptação e acomodação da lei dentro do arbítrio do juiz local, gerando conflitos e tensões entre a metrópole e a colônia e conflitos e tensões entre as próprias instâncias locais.

Com este espaço aberto, percebe-se que no desenvolvimento da técnica legislativa portuguesa em relação às colônias brasileiras no século XVI e XVII, o arbítrio e os costumes, locais e régios, funcionam como mecanismos de "governação" da metrópole em relação à colônia, assim como de organização da própria colônia em suas variadas jurisdições, conformando esse processo administrativo e legislativo português no exercício do Direito e da Justiça na América colonial.

Tais mecanismos de "governação", o arbítrio e os costumes, são decorrentes da interpretação do juiz. Desta forma, segundo os exemplos analisados, as normas régias valem-se do arbítrio do juiz e dos costumes reais como forma de garantir, preservar e legitimar a sua autoridade e legislação na colônia. Já os juízes locais utilizam a autonomia cedida pelo rei para sentenciarem 
de acordo com a interpretação mais provável dos fatos. Conforme a sua experiência, nos casos concretos e particulares, os juízes podem considerar os usos e costumes locais, e outros princípios interpretativos, como aplicações da lei e formadores do direito, nem que para isso seja preciso adaptar, acomodar e até revogar a norma régia, estabelecendo com esses mecanismos uma forma de "governação" local.

Tais mecanismos evidenciam a distância entre a teoria e a prática legal possibilitando entender o costume como um criador do direito, e não apenas a lei régia. Isto nos permite pensar em variadas maneiras de se exercer o poder judiciário, em lugar de uma única maneira. E, como observado nessa análise sobre os "Regimentos" e Autos de Correições, os costumes dos reinos são mais preservados e validados como criadores do direito do que os costumes e usos locais, normalmente tidos como contrários à lei. Ou seja, há a possibilidade de se entender o costume como principal criador do direito ao invés da lei régia, porém, esse costume é aproveitado no arbítrio do julgador, espaço que lhe é fornecido para agir, prudentemente, como melhor lhe parecer, do que como uma prática coletiva em si tentando manifestar um poder político.

Percebe-se, contudo, que se abriam malhas numerosas na disciplina, só aparentemente rígida dos regimentos. Neles estão descritas as vontades do rei e representadas o conjunto de normas disciplinadoras, regedoras, mas a norma que vigora é a particular, e 
até mesmo a vontade do rei pode ser combatida em prol do bem comum, defendido pela naturalidade do sistema jurídico de herança neotomista. Este sistema jurídico está baseado no pluralismo de estratégia probabilista, conferindo-lhe um caráter inconsistente que permite a negociação e as demais possibilidades pertinentes. Assim, pode-se afirmar que a estrutura administrativa do sistema político português no ultramar é heterogênea e ambígua. Esta estrutura apresenta tais características porque respondia às necessidades e conjunturas específicas de seu espaço, modificando-as e adaptandoas por meio de redes e conexões negociadas e tensas. A alteração nessa estrutura administrativa, feita para atender as necessidades tanto políticas quanto sociais, econômicas e culturais, parece ser um mecanismo de comunicação, negociação até mesmo, de conflito, entre o centro e a periferia capaz de conservar a "governação" desse sistema colonial.

\section{Referências Documentais}

MENDONÇA, Marcos Carneiro de. Raízes da Formação

Administrativa do Brasil. Tomo I. Instituto Histórico e Geográfico Brasileiro: Conselho Federal de Cultura, 1972.

TOURINHO, Eduardo. Autos de Correições de Ouvidores do Rio de Janeiro, 1624-1699. Tomo I. Rio de Janeiro: Prefeitura do Distrito Federal, 1929. 


\section{Referências Bibliográficas}

AQUINO, Tomás de. Suma Teológica. Vol. IV. São Paulo: Edições Loyola, 2005.

HESPANHA, António Manuel. "Direito comum e direito colonial".

Panóptica, Vitória, ano1, n.3, p.95-116, nov. 2006. Disponível em: $<$ http:www.parótica.org> Acesso em:05/11/2010.

. As estruturas políticas em Portugal na Época Moderna. In: MATTOSO, José. et all;

HOMEM, António Pedro Barbas. JUDEX PERFECTUS. Função Jurisdicional e Estatuto Judicial em Portugal - 1640-1820. Coimbra: Almedina, 2003.

PRODI, Paolo. Uma história da justiça. São Paulo: Martins Fontes, 2005.

RUIZ, Rafael. Hermenêutica e Justiça na América do século XVII. Anais do XXVI Simpósio Nacional de História - ANPUH. São Paulo, julho 2011. Disponível em http://www.snh2011.anpuh.org/resources/anais/14/1300290841_AR QUIVO_HermeneuticaejusticanaAmericadoseculoXVII(ANPUH).p df Acesso em: 10/09/2011.

"O papel da Consciência como forma de negociação dos poderes locais na América." IV Congresso Internacional de História - Maringá - Paraná - Brasil, setembro de 2009. 
Cadernos de Clio, Curitiba, n. ${ }^{\circ}$ 3, 2012

Disponível em http://www.pph.uem.br/cih/anais/trabalhos/105.pdf Acesso em: 20/02/2011.

, "Os espaços da ambigüidade: os poderes locais e a justiça na América do século XVII.” Revista de História, São Paulo, n.163, p.81-101, ago/dez 2010. Disponível em http://www.revistasusp.sibi.usp.br/scielo.php?pid=S003483092010000200004\&script=sci_arttext Acesso em: 03/02/2011. TENGARrinha, José (org.) História de Portugal. Bauru: EDUSC; São Paulo:UNESP; Portugal: Instituto Camões, 2001. 